\title{
Managing relationship gaps: A practitioner perspective
}

\author{
Fredrik Nordin (corresponding author)* and Annika Ravald** \\ * Department of Marketing, Stockholm Business School, Stockholm University, SE- \\ 10691 Stockholm, Sweden, Tel +46 8163309, fn@sbs.su.se \\ ** Hanken School of Economics, P.O.BOX 287, FIN-65101, Vaasa, Finland, \\ annika.ravald@hanken.fi
}

Original Publication:

Nordin, F. and Ravald, A. (2016), "Managing relationship gaps: A practitioner perspective”, Journal of Business Research, Vol. 69.

doi:10.1016/j.jbusres.2016.02.018

Copyright: Elsevier

http://www.elsevier.com

\begin{abstract}
Prior research has failed to explain how practitioners manage relationship gaps, i.e., situations where the interests of the parties in the relationship no longer match. By adopting a practice-based research approach to explain empirical findings drawn from industrial (B2B) service contexts, this study contributes an explanatory framework of how practitioners handle
\end{abstract}


relationship gaps in practice and what factors guide and shape their behaviors. This analysis is based on work life stories from practitioners at six different industrial companies and shows that relationship gaps are managed through four alternative gap management practices, each characterized by a specific set of activities. The practitioner's perception of the validity and feasibility of the available options guide the scope of action within which different sets of activities are enacted.

Key words: relationship dynamics, business-to-business relationships, servitization, strategy-as-practice, adaptation 


\section{Managing relationship gaps: A practitioner perspective}

\section{Introduction}

"We recently lost one of our major end customers that unexpectedly decided to outsource their service activities to a large, specialized full-service company. We were not able to align our product portfolio with their changed expectations and our previously harmonious and mutually beneficial relationship suddenly came to an end."

In a recent meeting, a manager from a leading supplier of industrial goods and services brought up the challenges related to the management of customer relationships. Extant research on relationship management has emphasized the positive consequences to be gained from longterm relationships with customers (e.g., Grönroos, 2006, Lindgreen and Wynstra, 2005). In turbulent and competitive markets, however, it is not always easy to maintain established relationships (e.g., Christensen and Overdorf, 2000), as the quote above illustrates. A long-term relationship might suddenly enter a critical phase as the customer's needs change, or when the supplier's product portfolio and strategy change, both perhaps driven by changes in the business environment. In effect, the solution offered by the supplier becomes "misaligned" (Corsaro and Snehota, 2011), and the future of the business relationship becomes uncertain (see Tähtinen and Blois, 2011). In other words, a relationship "gap" (Leminen, 2001), “conflict” (Hadjikhani and Håkansson, 1996), or “frictional event” (Nordin, 2006) emerges.

In this paper, we use the term "relationship gap" to describe a situation where the interests of the parties in the relationship no longer match. Specifically, we are concerned with the management of relationship gaps that emerge when a supplier in the industrial market shifts from a product-based business logic to a service-based one (e.g., Grönroos and Ravald, 2011), thereby redefining the content of the relationship. This focus is timely given the growing interest in service-oriented business logics in industrial companies (e.g., Gebauer et al., 2011). 
Previous research on relationship gaps has generally focused on specific strategies for managing relationship gaps, such as adapting to the requirements of the customer (e.g., Mukherji and Francis, 2008), recovering the relationship (e.g., Salo et al., 2009), or ending the relationship (e.g., Holmlund and Hobbs, 2009). However, in practice, the resolution of a gap situation depends on a variety of factors that must be considered and made sense of by the managers involved. Adapting to customer requirements (Corsaro and Snehota, 2011) may conflict with strategic objectives, while ending the relationship may result in the loss of an important customer. Various bondings (e.g., Ahmad and Buttle, 2001) and situational circumstances, e.g., time pressure and competition, complicate the situation further. Managers must find a way forward in light of the contexture of these interdependent factors, e.g., organizational and industry-specific procedures, strategic agendas, and personal capabilities, as well as the specific features of the gap situation. Although there has been some in-depth research on relationship management describing processes related to adaptation and the recovery of relationships (Ahmad and Buttle, 2001, Salo et al., 2009), extant research seems to lack a "practical touch" in explaining managers' behaviors when handling relationship gaps. The purpose of this paper is to address this void in the relationship management literature and to contribute a framework that explains: (1) how relationship gaps are handled in practice, and (2) what factors guide how they are handled.

Drawing on the strategy-as-practice research approach (s-as-p), we focus on how practitioners who are involved in the management of customer relationships handle gap situations. As framed by, e.g., Jarzabkowski (2004) and Whittington (2006), s-as-p assumes that strategy is something that firms and people do, rather than something they have. In the same vein, relationship management can be interpreted as something organizational actors do that has an impact on the management of customer relationships at the organizational level. By adopting an s-as-p approach, we can gain a deeper understanding of the interplay between the 
contextual complexity surrounding relationship gap situations, the considerations taken into account by practitioners, and how these guide the practitioners' gap management behaviors.

The remainder of the article is organized as follows: First, we present a review of the literature related to the management of relationship gaps through adaptations, influence strategies, and ending. Second, we describe our research approach and empirical setting. Finally, the findings are presented and discussed, along with implications for managers and future research.

\section{Literature review}

From the provider's perspective, the management of relationship gaps logically follows three fundamental courses of action: making minor or major adaptations to better meet the expectations of the customer, making the customer adapt to the solution offered, or, when no other alternative seems feasible, ending the relationship.

The adaptation to customers in business-to-business (B2B) relationships, in terms of activities and modifications aimed at maintaining and improving relationships, is a wellresearched phenomenon (Hallén et al., 1991, Ahmad and Buttle, 2001, Mukherji and Francis, 2008). Adaptations can be made in relation to product features, scheduling, personnel, contractual terms, and administrative routines (Håkansson, 1982, Hallén et al., 1991), as well as with regard to softer factors, such as skills, values, and attitudes (Möller and Wilson, 1995). Unbundling (Stremersch and Tellis, 2002) and customization (Gilmore and Pine, 1997) of offerings, as well as organizational arrangements that facilitate "skunk works" (Gwynne, 1997), are concrete examples of adaptive behaviors. The potential benefits of adaptation include positive influences on revenue, cost savings, and customer retention (Möller and Wilson, 1995, Schmidt et al., 2007), along with increased trust (Hallén et al., 1991) and strengthened bonds between parties involved (Johanson and Mattsson, 1987). Ahmad and Buttle (2001) listed a 
number of "bondings," i.e., financial, social, and structural, which are essentially adaptive in nature and serve as a means to build stronger ties with the customer.

Research on adaptation has primarily focused on how to strengthen customer relationships, rather than on how to resolve relationship gaps. The literature on relationship recovery, however, has explored the "actions the actors undertake to change a problematic relationship into a beneficial one" (Salo et al., 2009, p. 621), offering a somewhat different perspective on adaptation. According to Salo et al., (2009), relationship recovery is a strategy applied when the ending of a relationship is not possible or would cause severe damage, e.g., when the dissolution process and development of new relationships would be too costly. Conceptually, relationship recovery can be seen as a combination of reactive actions often associated with adaptation, i.e. investing in the relationship by aligning with customers' needs and wants, and developing joint plans or improving communications (Salo et al., 2009).

The second course of action aims at making the customer adopt the solution offered through influence strategies aimed at getting the counterpart to change (McFarland et al., 2006) and selling tactics (Dubinsky and Rudelius, 1981). Influence strategies are either coercive (e.g., threats) or non-coercive (e.g., information exchange and recommendations) strategies (McFarland et al., 2006). More concrete selling tactics include personal visits, writing letters, asking questions, using dramatic efforts to get attention (Dubinsky and Rudelius, 1981), and “visualizing" the value of service offerings (Kindström et al., 2012).

The third course of action, relationship ending (Halinen and Tähtinen, 2002, Holmlund and Hobbs, 2009), concerns the dissolution of all activity links, actor bonds, and resource ties. The ending of a relationship is often triggered by factors such as goal incongruence, conflicts, and unfairness in the relationship (Yang et al., 2012). By contrast, commitment to the relationship (Hocutt, 1998) and the profitability of the relationship (Holmlund and Hobbs, 
2009) can hinder relationship endings. Depending on the situation, the type of ending can be described as chosen, forced, natural, desired, or predetermined (Halinen and Tähtinen, 2002).

Altogether, many aspects related to the management of relationship gaps seem to be well researched. However, we argue that this research is largely prescriptive or descriptive in nature. Prescriptive works suggest what factors organizations should consider and what courses of action should be taken (e.g., Hallén et al., 1991, Kindström et al., 2012). On the other hand, Salo et al. (2009) and Ahmad and Buttle (2001) provide descriptions of various steps and actions taken by providers. Meanwhile, the explanation of the practical actions taken by practitioners in the face of relationship gaps seems limited. An investigation into the activities of practitioners in gap situations, and how these activities are shaped by internal and external factors influencing the sensemaking processes of practitioners, is thus a relevant research task. Hence, this paper uses ideas from practice theory as a starting point for data collection and analysis and may be seen as a response to criticism about a lack of empirically based and practice-oriented marketing research (see Skålén and Hackley, 2011).

\section{A practice-based approach for relationship management research}

Practice theory can be traced back to several different disciplines (see, e.g., Vaara and Whittington, 2012), but a common denominator is the focus on social activities and their microlevel construction in real social contexts. Orlikowski (2010) distinguished between three modes of conducting research with a practice theoretical approach: practice as phenomenon, practice as perspective, and practice as philosophy. Research that focuses on practice as phenomenon is committed to the understanding of "what happens in practice" (p. 23) and "everyday doings" (p. 28); practice as perspective looks at how embedding contexts shape practices. The study presented in this paper is a combination of these two modes of research.

In particular, we use s-as-p (see, e.g., Vaara and Whittington, 2012) to gain a deeper understanding of the management of relationship gaps and to capture those actions that 
compose the gap management practice. S-as-p emphasizes practitioner agency, situated action, and recursiveness in conjunction with adaptiveness (Jarzabkowski, 2004, Paroutis and Pettigrew, 2007) and reflects our view of practitioners as gap managers, i.e., they both play an active role in making sense of the situation at hand and, in turn, giving sense (Rouleau, 2005) to it through different courses of action.

Following these considerations and central definitions associated with practice theory (see, e.g., Jarzabkowski, 2004), we operationalize "gap management practices" as situated sets of activities that practitioners in industrial organizations engage in when handling relationship gaps. Their behavior is thus not merely a routine reproduction or the result of a "repository" from which they unconsciously draw to deal with novel situations (Chia, 2004). Instead, practitioners are seen as reflective actors who enact different adaptive and recursive practices (Jarzabkowski, 2004) according to their sensemaking of structural elements and individual predispositions. Organizations tend to have a "corporate mindset" (Paul, 2000) that reflects the "dominant logic" of how the employees of a company see the world (Bettis and Prahalad, 1995). Logically, the personalities, experiences, and habits of individual practitioners also influence their perceptions and their sensemaking processes (see Covin et al., 2001). Together, these create the habitus (Bourdieu, 1990) within which the practitioner forms an understanding of what behavior might be appropriate.

As a practical starting point for understanding such influences, we specifically draw on the conceptual lens introduced by Reckwitz (2002), later refined by Warde (2005) and Schau et al. (2009). This lens suggests that "background knowledge" in the form of understandings, know-how, states of emotion, and motivational knowledge shapes behaviors of practitioners, (Reckwitz, 2002). Warde (2005, p. 134) divided these components into what Schau et al. (2009) later called the three integrative "anatomical parts" of practice: (1) "understandings" (e.g., knowledge and tacit cultural templates), (2) “procedures" (e.g., explicit performance rules), and 
(3) "engagements" (e.g., emotional projects and purposes). By making sense of these "anatomical parts," practitioners find guidance on how to handle various gap situations.

\section{$4 \quad$ Empirical setting and research process}

The findings presented in this paper, derive from a three-year research project carried out in close cooperation with six industrial Europe-based firms in the industrial tools, gas, industrial automation equipment, industrial products, and automotive sectors.

These companies had an annual turnover of $€ 0,5$ billion to $€ 30$ billion, and between 1,000 and 100,000 employees. The firms were all in the middle of a servitization process and had thus recently begun to offer full-scale services and solutions, e.g., outcome-based contracts, maintenance solutions, and management of customers' operations. In some cases, these services were offered in response to explicit customer needs; in other cases, they were the result of the company's own strategic development.

One of the purposes of the research project was to analyze the challenges related to the implementation of the servitization process. One issue that informants raised almost immediately was the emergence of relationship gaps. Some customers questioned the benefits of long-term service contracts, others had low technological readiness, and some wanted a version of the solution that the supplier was not able to deliver. "These situations really give us a headache," informants stated. From a theoretical perspective, we felt that this topic was worth closer examination: how are such relationship gaps handled in practice? Our quest to gain a better understanding of the management of these kinds of gaps can thus be characterized as “problem-driven” (Ellis and Levy, 2008).

The research approach was qualitative and data was collected by organizing workshop discussions with the participating firms and conducting in-depth interviews with practitioners. In order to gain an "authentic" understanding of the informants' work-life experiences, we 
followed a semi-structured interview agenda that allowed a free-flowing, still focused, conversation (cf. Seale and Silverman, 1997).

In total, we held 5 workshop discussions and conducted 13 interviews with 15 practitioners over a period of three years. Each interview lasted between one and two hours, and was recorded and transcribed. The workshop discussions lasted between one and four hours. In addition to these more formal data collection avenues, close collaboration with the companies enabled a continuous and prolonged dialogue with informants, which resulted in rich and deep data on the studied phenomenon. This prolonged engagement resulted not only in rich and deep data but also a thorough understanding of the studied phenomenon and its context, thereby ensuring the credibility of the findings (Lincoln \& Guba 1985).

The informants (see Table 1) were knowledgeable about their company and its business model, thanks to their long career in the companies. They were also engaged in the management of relationship gaps and were in a position to provide detailed and relevant "work life stories" (see Bertaux and Delcroix, 2000).

Table 1:

Informant descriptions.

\begin{tabular}{|c|c|c|}
\hline $\begin{array}{c}\text { Informant } \\
\text { (pseudonyms) }\end{array}$ & Position & $\begin{array}{c}\text { Years in the } \\
\text { company } \\
\text { (some are } \\
\text { estimates) }\end{array}$ \\
\hline Aaron & Project Manager & 37 \\
\hline Barney & Product Manager & 10 \\
\hline Caleb & Sales Manager & 37 \\
\hline Dan & Manager, Field Service & 13 \\
\hline Eve & Manager, Administrative Service & 27 \\
\hline Floyd & Head of Market Services & 15 \\
\hline Gary & Sales Manager & 10 \\
\hline Hank & Senior Manager & 15 \\
\hline Ian & Global Project Manager & 20 \\
\hline
\end{tabular}




\begin{tabular}{|c|c|c|}
\hline Jack & Service Manager & 15 \\
\hline Karl & Senior Expert & 39 \\
\hline Larry & Project Development Manager & 12 \\
\hline Maria & Global Marketing Manager & 18 \\
\hline Nathan & Industrial Services Manager & 27 \\
\hline Oscar & Director, Business Development & 3 \\
\hline
\end{tabular}

Although ethnographical and ethno-methodological approaches are generally considered appropriate methods for studying practices (Samra-Fredericks, 2010), others argue that practitioners are able to effectively provide such stories in retrospect and reflect upon what they actually did (e.g., Paroutis and Pettigrew, 2007).

The scope of the research problem was split into two main themes: (1) gap management practices and their manifestation, and (2) anatomical parts of gap management practice, namely, understandings, procedures, and engagements. These anatomical parts served as our "sensitizing concepts" (Blumer, 1954), providing initial direction for our study and subsequent analysis. At the same time, they allowed for openness and flexibility, and the development of empirically grounded concepts from the data.

On the basis of an analysis of the initially collected data, we developed a tentative model describing different gap management practices and their embeddedness in the contexture of the gap situation. Throughout the study, we continuously and iteratively refined this model in line with insights drawn from the interviews and focus group sessions, and in comparison with relevant literature (see, e.g., Dubois and Gadde, 2002). When the final model began to emerge, we carried out a final coding using a text analysis tool (Weft QDA), dividing the collected data into four overall practices used to manage relationship gaps (convincing, combining, capitulating, and canceling). At this stage, we were also able to extract the sets of activities belonging to each practice and the influencing factors derived from the contexture of the gap situation. The continuous testing of the developed framework in close cooperation with 
practitioners from six different companies added robustness to the findings and conclusions. This type of member check is a means for ensuring the confirmability (Lincoln \& Guba 1985) of data in terms of both descriptive and interpretive validity (Maxwell 1992), both critical aspects of the trustworthiness of a qualitative study.

\section{$5 \quad$ Findings}

\subsection{Four gap management practices}

In this section, we address our first research question, i.e. How are relationship gaps handled in practice?, presenting the four main courses of action practitioners use to handle relationship gaps in practice: convincing, combining, capitulating, and canceling. Each of these practices is interpreted in terms of the practitioner's mode of behavior toward the customer, using two empirically grounded dimensions; complaisance and persistence (see Fig. 1).

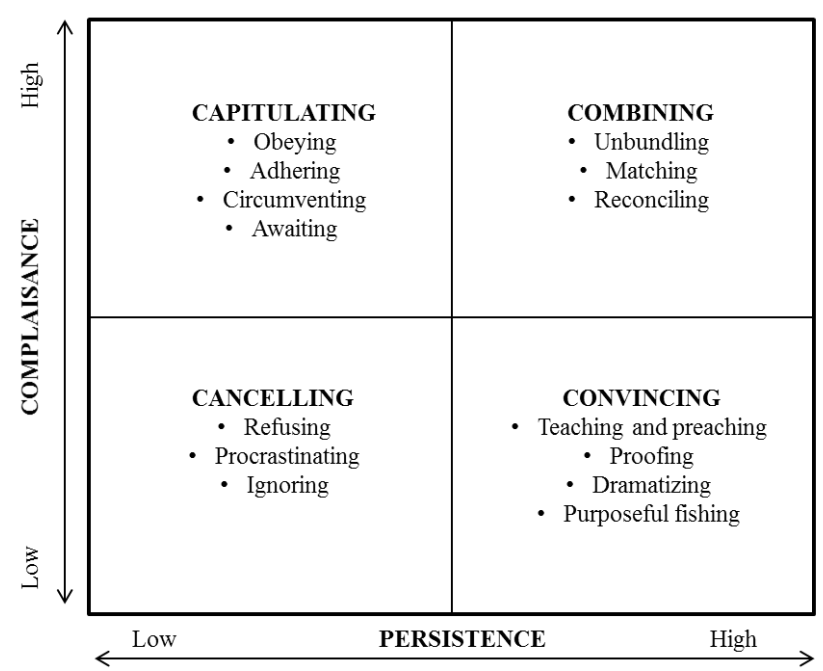

Fig. 1 The four gap management practices. 
Complaisance is defined as the degree of the practitioner's adjustment to the customer's expressed needs and wants, while persistence is the degree of the practitioner's sustained and focused efforts to persuade the customer to adopt the offered solution.

Below, we will present the four gap management practices along with their respective sets of activities.

\subsubsection{Convincing}

The practitioner's persistent behavior to persuade the customer to adopt the offered solution characterize the convincing practice. We identified four different activities related to this practice: (1) teaching and preaching, (2) proofing, (3) dramatization, and (4) purposeful fishing.

Teaching and preaching means that the practitioner strenuously tries to clarify the benefits of the offering to the customer, while still taking the customer's standpoint seriously. Various tools, such as tablets and presentation materials, were often used to strengthen the arguments. Proofing includes giving practical demonstrations, making simulations, and showing calculations aimed at offering a clearer picture of the functionality and value of the offering. Proving the benefits of a service is often difficult, and some practitioners acknowledged that they sometimes had to give away products free of charge, or lend them out for a period of time in order to allow the customer to experience the benefits for themselves. Practitioners also employed emotional techniques, such as scaring the customer or creating a guilty conscience. For example, possible negative consequences related to security issues were emphasized in order to play on customers' emotions and risk aversion. In line with Dubinsky and Rudelius (1981), we call this activity dramatization. Finally, we identified a more subtle and gentle activity in the data, which we call purposeful fishing. The practitioners try to elicit the customers' latent needs by asking carefully selected questions and the aim is to create aha- 
moments as the customers realize the potential gains for themselves. Empirical quotes illustrating these activities are presented in Table 2.

Table 2:

Convincing: activities and illustrative quotes.

\begin{tabular}{|l|l|}
\hline Activities & Illustrative quotes \\
\hline preaching & "I don't give up. I have to enlighten them, the masses living in the \\
can do for them in their business"
\end{tabular}

\subsubsection{Combining}

Combining involves the practitioner compromising between persistence and complaisance. It means that both parties involved in the relationship must adapt, and a compromise is developed that fulfills the requirements of both parties. Three underlying activities were identified: (1) unbundling, (2) matching, and (3) reconciling. 
Unbundling means that the practitioner suggests that the deal be broken up into smaller parts that can be handled separately, often with optional amendments for the future (see Stremersch and Tellis, 2002). The informants explained that it is often easier to negotiate several small deals than one large deal, since these may be handled lower down in the organizational hierarchy. Matching, in turn, means that the practitioner responds to the requests or objections presented by the customer by trying to find a compromise or alternative solution that will sufficiently match the needs and wants of both parties. The activity of reconciling resembles that of matching, but the focus here is rather on the foundation and definition of the continued relationship. In trying to unify the expectations of both actors, the role of the practitioner becomes that of a conciliator. This activity can sometimes result in the upstart of new projects co-developed with the customer. See Table 3 for empirical quotes of these activities.

Table 3:

Combining: activities and illustrative quotes.

\begin{tabular}{|l|l|}
\hline Activities & Illustrative quotes \\
\hline Unbundling & "It may be easier to offer several smaller pieces since decisions can be \\
made at a lower level in their organization"
\end{tabular}




\begin{tabular}{|l|l|}
\hline Reconciling & $\begin{array}{l}\text { "Sometimes the customer wants very technologically advanced } \\
\text { solutions. My role is to pass on the ideas to our engineering department } \\
\text { and try to convince them to have look at it. I mean, if the customers want } \\
\text { to start up a brand new tech process and want us as partners, absolutely" }\end{array}$ \\
\hline
\end{tabular}

\subsubsection{Capitulating}

The practice of capitulating means that the practitioner is complaisant and adopts the customer's explicit and implicit needs and wants without persisting with the initial standpoints. We identified four different capitulation activities: (1) obeying, (2) adhering, (3) circumventing, and (4) awaiting.

When obeying, the practitioner perceives that there is no other option than submitting to the customer's requests. The main driver here is the fear of losing an important customer; therefore, the negation power of the customer is decisive. The activity of adhering resembles obeying in that it implies adopting the customer's request. The difference here is that it is a more voluntary action; the practitioner understands and accepts the customer's needs, and is willing to act in accordance with these. Circumventing, on the other hand, is quite different, as the practitioner attempts to meet the customer's request, despite the fact that this behavior is not normally possible or allowed, e.g., by practicing skunk works to sidestep standard practices in the organization (see Gwynne, 1997). The practitioner subverts the provider's intended strategy by taking the customer's request to a separate organizational unit where it can be handled without interfering with existing operations. Finally, awaiting means that the practitioner expects the customer to change his or her viewpoint, patiently allowing the relationship to continue as before, for the time being. See Table 4 for empirical quotes of these activities. 


\section{Table 4:}

Capitulating: activities and illustrative quotes.

\begin{tabular}{|l|l|}
\hline Activities & Illustrative quotes \\
\hline Obeying & "Sometimes our customer says, this is not good enough and we just have \\
& to listen" \\
\hline Adhering & "After a while I realized that we could actually make money from it" \\
\hline Circumventing & "We actually have a separate organization in our company where \\
& andicularly discordant customer requests can be handled" \\
\hline
\end{tabular}

\subsubsection{Canceling}

Canceling is a special kind of practice, as it implies the ending of a relationship as neither the provider nor the customer is willing to adapt to the other party. The practitioner is persistent and takes few actions to find a resolution that would result in the continuation of the relationship. Although it might seem like the practitioner is inactive in this practice, he or she still engages in specific activities, which we categorize as (1) refusing, (2) procrastinating, and (3) ignoring.

Refusing implies a reluctance to listen to the customer and to change, as it is perceived to be an impossible option. A lack of contract agreements, support for negotiating service agreements, and feasible infrastructure or necessary capabilities may cause this stance. Incompatible values might also be a reason. When procrastinating, the practitioner hesitates 
over taking appropriate measures. The practitioner thus delay or slow down changes to accommodate customers' requests until further notice. Such delays may be due to existing product or production plans. Lastly, ignoring means that the practitioner ignores the customer because the effort needed to find a positive resolution to the relationship gap is perceived to be too great and not worthwhile.

The practice of canceling may sometimes lead to undesirable outcomes. However, in many cases, canceling is inevitable and should not be regarded as a failure. If the gap between parties is great and the environment is not conducive to overcoming this gap, it is often appropriate to end the relationship. One informant explained that sometimes the accommodation of customers' needs requires the development of a completely new infrastructure. In such a case, it does not matter how much the practitioner wants to bridge the gap between the customer and provider, as it is simply not logistically feasible. See Table 5 for empirical quotes of activities associated with canceling.

\section{Table 5:}

Canceling activities and illustrative quotes.

\begin{tabular}{|l|l|}
\hline Activities & Illustrative quotes \\
\hline Refusing & "We have customers with all sorts of ideas, sometimes even violating \\
& laws and regulations. If their ideas are in conflict with our view of \\
\hline Procrastinating & "We do not accelerate, we rather slow down a little and put this customer \\
& aside for the moment being" \\
\hline
\end{tabular}




\begin{tabular}{|l|l|}
\hline Ignoring & $\begin{array}{l}\text { "If their answer is no, and we realize that we will not get through with } \\
\text { our offering at a fair profit, then we disconnect the system and leave } \\
\text { them alone" }\end{array}$ \\
\hline
\end{tabular}

\subsection{The anatomy of the four gap management practices}

In this section, we present the findings related to our second research question, i.e., What factors guide how relationship gaps are handled? The empirical findings support the notion that "actors deploy practices reflectively" (Seidl and Whittington, 2014). Thus, in accordance with Jarzabkowski's concept of "practices-in-use" (Jarzabkowski, 2004), we posit that practitioners enact gap management practices reflectively and exploratively, based on their sensemaking of the gap situation and its contexture, i.e. the anatomical parts (see Schau et al., 2009, p. 35), derived through a set of considerations.

The analysis of the empirical data revealed four main considerations that can be grouped together into two aggregate influencing factors: First, the perceived validity of the different gap management practices is an influencing factor that contains two considerations: the perceived significance of the offering for the provider in combination with the perceived significance of the customer relationship. Second, the perceived feasibility of different gap management practices is an influencing factor that is related to the practitioner's consideration of the procedural compatibility between the organizational context and the customer's demands, and his or her own value argumentation capability.

\subsubsection{Perceived validity of different gap management practices}

Perceived validity is the result of a sensemaking process whereby the practitioner is influenced both by his or her own personal frame of reference and mindset, and by the organizational context and culture. Since this perception involves the practitioner's emotions 
beyond what is specified by explicit strategies, procedures, and knowledge, it is emotionally charged and can be difficult to change.

More specifically, the findings suggest two key aspects. First, a high perceived significance of the customer tends to lead to complaisance (i.e., the enactment of either combining or capitulating). Although structural invariants, such as the power influence of the specific customer, are certainly essential, it is the practitioner's perception of such aspects that matters. One informant explained how customer demands were regarded in his company: "The customer must always win on what we do, it is our guiding principle. Our industry is based on relationships, not just selling anything and leaving." Another informant acknowledged that "if you have a customer that pays and that wants a 'trike' or whatever... you just have to fix it," implying that valuable customers almost always possess negotiation power. Second, a high perceived significance of the offering for the provider tends to lead to persistence (i.e., the practices of convincing and combining). This refers to situations where the practitioner perceives that it is important to stick to the intended agenda, e.g., the offering developed for sale. This often requires perseverance: "We try in many ways, we are out and evangelize, run courses, and do a lot to explain our technology and convince our customers."

\subsubsection{Perceived feasibility of different gap management practices}

Whereas "perceived validity" can be described as an emotionally charged intention, “perceived feasibility" is more grounded in the practitioners' explicit knowledge of the situation and of the procedures and rules influencing the kinds of behaviors that are feasible. Perceived feasibility may, thus, be compared with Warde's (2005) and Schau et al's (2009) conception of procedures and understandings. Knowledge of organizational procedures and rules affect how practitioners perceive the feasibility of different practices. Such procedures and rules may be both internal (e.g., internal instructions and guidelines) and external (e.g., laws and regulations) to the organization. They influence the behavior of the practitioner by steering him or her 
toward certain types of gap management practices and away from others. For instance, if an organization has done something in a particular way for a long time, written or unwritten procedures may have been established that can be difficult or even inappropriate to change.

More specifically, the findings concerning the perceived feasibility suggest two key aspects. First, a high perceived procedural compatibility with the customer's demands tends to lead to complaisance (i.e., the enactment of either capitulating or combining). In other words, laws and regulations, logistics infrastructures, and internal procedures influence the practitioners' behaviors to various degrees depending on their nature and the extent to which they are known and respected. One informant illustrated the importance of procedural compatibility, mentioning the possible influence of one of the strictest factors - laws and regulations: "There are more laws and regulations that we should follow than some of us are aware of." The organizational procedures and systems might also hinder adaptive practices: "There is an inner tardiness in our systems that hinder a smooth implementation of new ideas."

Second, a high value argumentation capability, i.e., the practitioner's level of knowledge regarding customer processes, application expertise, and ability to offer credible, convincing arguments for adoption, tends to lead to persistence (i.e., the enactment of convincing or combining). As one informant explained: "If they claim that they had this product for ten years and that it keeps going though they never served it, then it's a bit difficult to argue for benefits related to avoidance of breakdowns - it just does not bite.”

\section{Discussion and implications}

\subsection{Discussion of the results}

While relationship gaps can emerge for several reasons, the alternative courses of action to resolve them can be reduced to four main practices: convincing, combining, capitulating, and canceling. Each of these involves a set of activities that the practitioner applies depending on 
how he or she perceives the contexture of different gap situations. We conclude that practitioners handle gap situations by first making sense of the situation through the perceived validity and feasibility of different courses of action and subsequently by giving sense to it through the enactment of various combinations of persistent or complaisant activities (see Gioia and Chittipeddi, 1991, Rouleau, 2005). The findings can be condensed into two fundamental propositions:

First, the higher the perceived significance of the offering for the provider in conjunction with a high perceived confidence in one's own value argumentation capability, the more likely it is that the practitioner's sensemaking process will result in persistent behavior, i.e., convincing or combining practices. Second, the higher the perceived significance of the customer relationship in conjunction with a high perceived procedural compatibility, the more likely it is that the practitioner's sensemaking process will result in complaisant behavior, i.e., capitulating or combining practices. In effect, gap management practices can essentially be conceptualized as functions of the complaisant and persistent relationship gap behaviors enacted by practitioners; these behaviors, in turn, are the result of practitioners' perceptions of what courses of actions are valid and feasible for handling the gap (see Fig. 2).

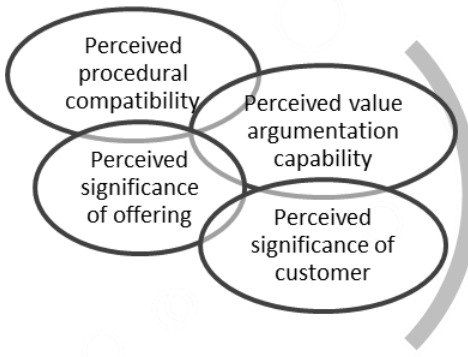

Considerations

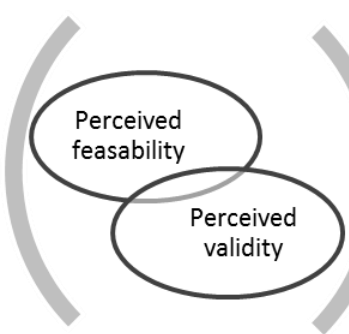

Influencing factors

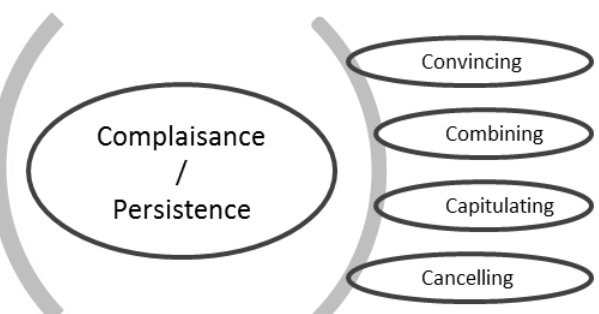

Behavior

Practice

Fig 2. The anatomy of gap management practice. 


\subsection{Research contribution}

Relationship management scholars have long emphasized the dynamics of the relationships between actors in industrial markets as a central research topic. The contribution of this paper to this area of research is twofold.

Firstly, by focusing explicitly on the role of practitioners and their behaviors when handling relationship gap situations, we contribute a new layer to the literature on relationship management that has hitherto not been sufficiently addressed. The s-as-p lens implies that practitioners, as a salient part of the provider-customer interface, can be regarded as those members of the provider organization who have the resolution of the relationship gap in their hands. Their behaviors, in terms of complaisance and persistence, determine how situations where the interests of the parties no longer match, are resolved. In a way, practitioners set the direction for the future of an existing relationship, confirming the s-as-p assumption adopted in this paper, i.e. that relationship management can be interpreted as something organizational actors (specifically those interacting directly with customers) do. Thus, by taking the practitioner's perspective, we respond to calls for more “'bottom-up' empirical research into how marketing is actually done in organizations" (Skålén and Hackley, 2011, p. 189), thereby adding a new layer to the hitherto primarily managerial perspective in relationship management research.

Secondly, the proposed framework of how practitioners handle relationship gaps in practice, and what factors guide and shape their behaviors in these situations, is explanatory in nature. In contrast to much of the extant literature on relationship management, this paper is thus neither prescriptive (e.g., Hallén et al, 1991, Kindström et al., 2012) nor merely descriptive (e.g., Salo et al., 2009, Ahmad and Buttle, 2001). By approaching the phenomenon under study through an s-as-p lens, we arrive at a deeper understanding of the interplay between the contexture of the gap situation, the considerations practitioners take into account, and how these 
guide the practitioners' gap management behaviors. The findings presented here disclose the gap situation as perceived by the practitioner, the means he or she applies for handling the situation, reflectively and exploratively, with an aim to resolve the situation. This also means that this study has a novel entry point to examine relationship management. While the focus in this study is on practices per se, a majority of extant research focus on the process towards a specific intended outcome, i.e. relationship endings (Halinen and Tähtinen, 2002, Holmlund and Hobbs, 2009), recovery (Salo et al., 2009), and adaptations (Mukherji and Francis, 2008).

\subsection{Managerial implications}

The inspiration for this study comes from managers' ambitions to find appropriate solutions to relationship gaps that emerge when suppliers redefine the content of relationships with existing customers. The results presented in this paper might not fulfill managers' requests for a toolbox or roadmap explaining how different gap situations are to be resolved. Instead, the results provide an understanding of the contexture within which the relationship gap is embedded and how a web of entangled conditions shape managers' behaviors. As such, the findings have implications at both the managerial level and the practitioner level.

At the managerial level, it is important to realize that practitioners' behaviors are linked to the contexture of the gap situation through their individual sensemaking processes. The perceived validity and feasibility of different gap management practices form the basis of this sensemaking. It is thus important to ensure that the preconditions for implementing new strategies, i.e., so-called structural elements, support the practitioners who handle gap situations. The successful management of relationship gaps may, for instance, require the revision of the underlying circumstances that influence what is perceived to be an appropriate or feasible course of action. If there is no supporting infrastructure conducive to the customer's requirements, the focus should perhaps be on developing the requisite infrastructure, instead of just ending the relationship. On the other hand, capitulating may result in the neglect of the 
industrial company's strategic objectives, and, perhaps, the value argumentation capabilities of practitioners should be developed. By looking at the framework in this way, it can become a powerful strategic development tool.

The findings presented here enhance practitioners' understanding of the scope involved in the resolution of gap situations. The framework depicts the various constituents of the process, providing labels and meanings for what is done in terms of behaviors (complaisant/persistent), activities (e.g., dramatizing, reconciling, circumventing, refusing) and influencing factors (perceived validity/feasibility). By enabling a deeper understanding of the contexture of the gap situation and how their behaviors are shaped, practitioners are better prepared to arrive at the desired resolutions of relationship gaps.

\subsection{Limitations and suggestions for further research}

The framework reported in this paper is an attempt to explain how relationship gaps are handled in practice, based on the work-life stories of practitioners. To validate the results and eliminate any possible post-hoc rationalization bias on the part of these practitioners, a logical extension could be to adopt an even closer research approach, such as participant observation (Samra-Fredericks, 2010). In doing so, the "situated actions" (Suchman, 1987), stories, and reasoning of improvising practitioners could be studied in real time. The framework delineated in this paper could serve as a sensitizing starting point for such a study, providing a road map for making sense of the observed sayings and doings of practitioners.

Secondly, the research setting in this study was confined to industrial companies facing relationship gaps that emerged as the result of a servitization process. It seems reasonable to assume that the main conclusions of our study have high external validity. Nonetheless, by widening the scope of the empirical setting and analyzing other types of relationship gaps in other types of business contexts, the current research could be expanded. For instance, how are the different gap management practices manifested in situations where it is the customer who 
initiates the redefinition of the relationship? Furthermore, how are relationship gaps handled in business contexts characterized by high turbulence, such as high-technology contexts, where mismatches between actors can be assumed to emerge frequently? Such research endeavors could subsequently be followed up with quantitative testing based on broader empirical material.

A third limitation of the results and conclusions presented above is the one-sided focus on the industrial provider. Future research could accordingly focus on the collective sensemaking of several actors from both sides of the relationship. The resolution of a relationship gap, after all, takes a joint effort from both sides of a relationship.

\section{References}

Ahmad, R. and Buttle, F. (2001). "Retaining business customers through adaptation and bonding: a case study of HDoX." Journal of Business \& Industrial Marketing, Vol 16, No 7, pp. 553-573.

Bertaux, D. and Delcroix, C. (2000). Case histories of families and social processes. The Turn to Biographical Methods in Social Science: Comparative Issues and Examples, P.

Chamberlayne, J. Bornat and T. Wengraf. Psychology Press, New York. 71-89.

Bettis, R. A. and Prahalad, C. K. (1995). "The dominant logic: retrospective and extension." Strategic Management Journal, Vol 16, No 1, pp. 5-14.

Blumer, H. (1954). "What is wrong with social theory?" American Sociological Review, Vol 19, No 1, pp. 3-10. 
Bourdieu, P. (1990). The logic of practice. Stanford University Press. Berkeley and Los Angeles.

Christensen, C. M. and Overdorf, M. (2000). "Meeting the challenge of disruptive change." Harvard Business Review, Vol 78, No 2, pp. 66-77.

Chia, R. (2004). "Strategy - as - practice: reflections on the research agenda." European Management Review, Vol 1, No 1, pp. 29-34.

Corsaro, D. and Snehota, I. (2011). "Alignment and misalignment in business relationships." Industrial Marketing Management, Vol 40, No 6, pp. 1042-1054.

Covin, J. G., Slevin, D. P. and Heeley, M. B. (2001). "Strategic decision making in an intuitive vs. technocratic mode: structural and environmental considerations." Journal of Business Research, Vol 52, No 1, pp. 51-67.

Dubinsky, A. J. and Rudelius, W. (1981). "Selling techniques for industrial products and services: are they different?" Journal of Personal Selling \& Sales Management, Vol 1, No 1, pp. 65-75.

Dubois, A. and Gadde, L.-E. (2002). "Systematic Combining - An abductive approach to case research." Journal of Business Research, Vol 55, No 7, pp. 553-560.

Ellis, T. J. and Levy, Y. (2008). "Framework of problem-based research: a guide for novice researchers on the development of a research-worthy problem." Informing Science: International Journal of an Emerging Transdiscipline, Vol 11, No, pp. 17-33. 
Gebauer, H., Gustafsson, A. and Witell, L. (2011). "Competitive advantage through service differentiation by manufacturing companies." Journal of Business Research, Vol 64, No 12, pp. $1270-1280$.

Gilmore, J. H. and Pine, J. H. (1997). "The four faces of mass customization." Harvard Business Review, Vol 75, No 1, pp. 91-101.

Gioia, D. A. and Chittipeddi, K. (1991). "Sensemaking and sensegiving in strategic change initiation." Strategic Management Journal, Vol 12, No 6, pp. 433-448.

Grönroos, C. (2006). "On defining marketing: finding a new roadmap for marketing." Marketing Theory, Vol 6, No 4, pp. 395-417.

Grönroos, C. and Ravald, A. (2011). "Service as business logic: implications for value creation and marketing." Journal of Service Management, Vol 22, No 1, pp. 5-22.

Gwynne, P. (1997). "Skunk works, 1990s-style." Research-Technology Management, Vol 40, No 4, pp. 18-23.

Hadjikhani, A. and Håkansson, H. (1996). "Political actions in business networks a Swedish case." International journal of research in marketing, Vol 13, No 5, pp. 431-447.

Halinen, A. and Tähtinen, J. (2002). "A process theory of relationship ending." International Journal of Service Industry Management, Vol 13, No 2, pp. 163-180. 
Hallén, L., Johansson, J. and Seyed-Mohamed, N. (1991). "Interfirm adaptation in business relationships." Journal of Marketing, Vol 55, No 2, pp. 29-37.

Hocutt, M. A. (1998). "Relationship dissolution model: antecedents of relationship commitment and the likelihood of dissolving a relationship." International Journal of Service Industry Management, Vol 9, No 2, pp. 189-200.

Holmlund, M. and Hobbs, P. (2009). "Seller-initiated relationship ending: an empirical study of professional business-to-business services." Managing Service Quality, Vol 19, No 3, pp. 266-285.

Håkansson, H., Ed. (1982). International marketing and purchasing of industrial goods. John Wiley \& Sons, Ltd. Chichester.

Jarzabkowski, P. (2004). "Strategy as practice: recursiveness, adaptation, and practices-inuse." Organization Studies, Vol 25, No 4, pp. 529-560.

Jarzabkowski, P., Balogun, J. and Seidl, D. (2007). "Strategizing: the challenges of a practice perspective." Human Relations, Vol 60, No 1, pp. 5-27.

Johanson, J. and Mattsson, L.-G. (1987). "Interorganizational relations in industrial systems: a network approach compared with the transaction-cost approach." International Studies of Management \& Organization, Vol 17, No 1, pp. 34-48. 
Kindström, D., Kowalkowski, C. and Nordin, F. (2012). "Visualizing the value of servicebased offerings: empirical findings from the manufacturing industry." Journal of Business \& Industrial Marketing, Vol 27, No 7, pp. 538-546.

Leminen, S. (2001). "Gaps in buyer-seller relationships." Management Decision, Vol 39, No 3, pp. 180-189.

Lincoln, Y.S., and Guba E.G (1985). Naturalistic inquiry. Sage. Newbury Park, CA.

Lindgreen, A. and Wynstra, F. (2005). "Value in business markets: what do we know? Where are we going?" Industrial Marketing Management, Vol 35, No 7, pp. 732-748.

Makkonen, H., Olkkonen, R. and Halinen, A. (2012). "Organizational buying as muddling through: a practice-theory approach." Journal of Business Research, Vol 65, No 6, pp. 773780.

Maxwell, J. (1992). "Understanding and validity in qualitative research." Harvard educational review 62(3): 279-301.

McFarland, R. G., Challagalla, G. N. and Shervani, T. A. (2006). "Influence tactics for effective adaptive selling." Journal of Marketing, Vol 70, No October, pp. 103-117.

Mukherji, A. and Francis, J. D. (2008). "Mutual adaptation in buyer-supplier relationships." Journal of Business Research, Vol 61, No 2, pp. 154-161. 
Möller, K. and Wilson, D. T. (1995). Business marketing: An interaction and network perspective. Kluwer Academic Publishers. Dordrecht.

Nordin, F. (2006). "Identifying intraorganisational and interorganisational alliance conflicts a longitudinal study of an alliance pilot project in the high technology industry." Industrial Marketing Management, Vol 35, No 2, pp. 116-127.

Orlikowski, W. J. (2010). Practice in research: phenomenon, perspective and philosophy, Cambridge handbook of strategy as practice. Cambridge University Press, Cambridge, pp. 2333.

Paroutis, S. and Pettigrew, A. (2007). "Strategizing in the multi-business firm: strategy teams at multiple levels and over time." Human Relations, Vol 60, No 1, pp. 99-135.

Paul, H. (2000). "Creating a global mindset." Thunderbird International Business Review, Vol 42, No 2, pp. 187-200.

Payan, J. M. and McFarland, R. G. (2005). "Decomposing influence strategies: argument structure and dependence as determinants of the effectiveness of influence strategies in gaining channel member compliance." Journal of Marketing, Vol 69, No 3, pp. 66-79.

Reckwitz, A. (2002). "Toward a theory of social practices: a development in culturalist theorizing." European Journal of Social Theory, Vol 5, No 2, pp. 243-263. 
Rouleau, L. (2005). "Micro - practices of strategic sensemaking and sensegiving: how middle managers interpret and sell change every day." Journal of Management Studies, Vol 42, No 7, pp. 1413-1441.

Salo, A., Tähtinen, J. and Ulkuniemi, P. (2009). "Twists and turns of triadic business relationship recovery." Industrial Marketing Management, Vol 38, No 6, pp. 618-632.

Samra-Fredericks, D. (2010). Researching everyday practice: the ethnomethodological contribution. Cambridge Handbook of Strategy as Practice, Cambridge University Press. Cambridge.

Schau, H. J., Muñiz Jr., A. M. and Arnould, E. J. (2009). "How brand community practices create value." Journal of Marketing, Vol 73, No 5, pp. 30-51.

Schmidt, S.-O., Tyler, K. and Brennan, R. (2007). "Adaptation in inter-firm relationships: classification, motivation, calculation." Journal of Services Marketing, Vol 21, No 7, pp. 530537.

Seale, C. and D. Silverman (1997). "Ensuring rigour in qualitative research." The European Journal of Public Health, Vol 7, No 4, pp. 379-384.

Seidl, D. and Whittington, R. (2014). "Enlarging the strategy-as-practice research agenda: towards taller and flatter ontologies." Organization Studies, Vol 35, No 10, pp. 1407-1421. 
Skålén, P. and Hackley C. (2011). "Marketing-as-practice. Introduction to the special issue." Scandinavian Journal of Management, Vol 27, No 2, pp. 189-195.

Stremersch, S. and Tellis, W. (2002). "Strategic bundling of products and prices: a new synthesis for marketing." Journal of Marketing, Vol 66, No 1, pp. 55-72.

Suchman, L. (1987). Plans and situated action. Cambridge University Press. Cambridge Susman, G. I. and Evered, R. D. (1978). "An assessment of the scientific merits of action research." Administrative Science Quarterly, Vol 23, No 4, pp. 582-603.

Tähtinen, J. and Blois, K. (2011). "The involvement and influence of emotions in problematic business relationships." Industrial Marketing Management, Vol 40, No 6, pp. 907-918.

Vaara, E. and Whittington, R. (2012). "Strategy-as-practice: taking social practices seriously." The Academy of Management Annals, Vol 6, No 1, pp. 285-336.

Warde, A. (2005). "Consumption and theories of practice." Journal of Consumer Culture, Vol 5, No 2, pp. 131-153.

Whittington, R. (2006). "Completing the practice turn in strategy research." Organization Studies, Vol 27, No 5, pp. 613-634. 
Yang, D., Sivadas, E., Kang, B. and Oh, S. (2012). "Dissolution intention in channel relationships: An examination of contributing factors." Industrial Marketing Management, Vol 41, No 7, pp. 1106-1113. 